\title{
Abdominal duvar endometriozisi; Retrospektif, gözlemsel bir çalışma
}

\section{Abdominal wall endometriosis; A retrospective, observational study}

\author{
Mehmet Kağan KATAR ${ }^{*} \square$, Deniz TiKici²
}

${ }^{1}$ Yozgat Bozok Üniversitesi Tıp Fakültesi, Genel Cerrahi Anabilim Dalı, Yozgat/TÜRKiYE

${ }^{2}$ Mersin Üniversitesi Tıp Fakültesi, Genel Cerrahi Anabilim Dalı, Mersin/TÜRKIYE

\section{Öz}

Amaç: Bu çalışmanın amacı, abdominal duvar endometriozisi (ADE) olan hastalarda demografik ve klinik özellikleri, tanı araçlarını, cerrahi seçenekleri ve nüks oranlarını değerlendirmektir.

Gereç ve Yöntemler: Ocak 2015 ile Ocak 2020 tarihleri arasından kliniğimizde ADE nedeniyle opere edilen 44 hasta çalışmaya dahil edildi. Hastalara ait demografik veriler, operasyon geçmişi, klinik özellikler, tanı için kullanılan görüntüleme yöntemi, uygulanan operasyon tipi ve rekürrens durumu değerlendirildi.

Bulgular: Çalışmaya dahil edilen hastaların, yaşlarının median değeri 35 (26-48) olarak belirlendi. Hastalardan 1 (\%2,3)'inin abdominal operasyon öyküsü bulunmazken; 39 (\%88,6) hastanın cesarean section (C/S), $2(\% 4,5)$ hastanın myomektomi ve $2(\% 4,5)$ hastanın da histerektomi öyküsü bulunmaktadır. Çalışmaya dahil edilen hastalardan $2(\% 4,5)$ 'sinin herhangi bir şikayeti bulunmazken, $31(\% 70,5)$ hastada karın ön duvarında kitle ve $39(\% 88,6)$ hastada ise ağrı şikayeti bulunmaktaydı. ADE'nin $23(\% 52,3)$ hastada pfannenstiel insizyonun sol lateralinde ve $17(\% 38,6)$ hastada ise pfannenstiel insizyonun sağ lateralinde olmak üzere, büyük çoğunluğunun pfannenstiel insizyon hattında olduğu tespit edildi. Hastaların 34'ünde preoperatif tanı aracı olarak abdominal ultrasonografi (US) ve 10 hastada da abdominopelvik bilgisayarlı tomografi (BT) kullanılmıştır. Abdominal US'nin doğruluk oranının \%85,2, abdominopelvik BT'nin doğruluk oranının ise \%50 olduğu belirlenmiştir. Serimizdeki takip oranı \%95,4 iken, takip süresi median değerinin 36,5 ay (13-57) olduğu gösterilmiştir. Ayrıca takipteki hastalardan birinde rekürrens geliştiği görülmüştür.

Sonuç: $A D E$, jinekolojik girişim öyküsü olan ve abdominal insizyon bölgesinde siklik ağrı ve şişlik ile gelen reprodüktif çağdaki tüm kadınlarda akla gelmelidir. Preoperatif tanı için, hastanın öyküsü ayrıntılı olarak sorgulanmalı; dikkatli bir fizik muayene yapılmalı ve tanı için abdominal US kullanılmalıdır. Tedavide cerrahi eksizyon tercih edilmelidir.

Anahtar kelimeler: Endometriozis; karın duvarı; siklik ağrı; kitle

Sorumlu Yazar*: Mehmet Kağan KATAR, Yozgat Bozok Üniversitesi Tıp Fakültesi, Genel Cerrahi Anabilim Dalı, Yozgat/TÜRKIYE E-posta: drkagankatar@gmail.com

ORCID: 0000-0002-1599-5456

Gönderim: 12/01/2021 kabul: 08/03/2021

Doi: $10.18663 /$ tjcl.859676 


\begin{abstract}
Aim: The aim of this study is to evaluate demographic and clinical characteristics, diagnostic tools, surgical options and recurrence rates in patients with abdominal wall endometriosis (AWE).
\end{abstract}

Material and Methods: 44 patients who were operated for AWE in our clinic between January 2015 and January 2020 were included in the study. Demographic data of the patients, operation history, clinical features, imaging method used for diagnosis, type of operation performed and recurrence status were evaluated.

Results: The median age of the patients included in the study was determined as 35 (26-48). While 1 (2.3\%) of the patients did not have a history of abdominal operation; 39 (88.6\%) patients had cesarean section (C / S), 2 (4.5\%) patients had myomectomy and 2 (4.5\%) patients had hysterectomy history. In addition, $2(4.5 \%)$ of the patients included in the study had no complaints, while 31 (70.5\%) patients had a mass in the anterior abdominal wall and 39 (88.6\%) patients had pain. AWE was in the left lateral of the pfannenstiel incision in $23(52.3 \%)$ patients and in the right lateral of the pfannenstiel incision in 17 (38.6\%) patients; the majority of them were found to be in the pfannenstiel incision. Abdominal ultrasonography (US) was used as a preoperative diagnostic tool in 34 of the patients and abdominapelvic computed tomography (CT) was used in 10 patients. It was determined that the accuracy rate of abdominal US was $85.2 \%$, and the accuracy rate of abdominopelvic CT was $50 \%$. While the follow-up rate in our series was $95.4 \%$, the median value of follow-up period was 36.5 months (13-57). In addition, recurrence was observed in one of the patients followed up.

Conclusion: AWE should be considered in all women of reproductive age who have a history of gynecological intervention and present with cyclic pain and swelling at the abdominal incision. For preoperative diagnosis, the patient's history should be questioned in detail; a careful physical examination should be performed, and abdominal US should be used for diagnosis. Surgical excision should be preferred in treatment.

Keywords: Endometriosis; abdominal wall; cyclic pain; mass

\section{Giriş}

Endometriozis, endometrium dokusunun endometrial kavite dışında bulunması olarak tanımlanır.[1] Reprodüktif çağdaki kadınlarda insidansının\%5-15 civarında olduğu bildirilmektedir. [2] Endopelvik alanda gelişebileceği gibi beyin, akciğer, umblikus, inguinal bölge veya insizyon skarı gibi ekstrapelvik alanda da gelişebildiği bildirilmiştir.[3,4] Abdominal duvar endometriozisi (ADE), subkutan adipoz dokuda veya karın duvarının muskuler tabakasında endometrium dokusunun varlığı ile karakterize nadir bir durumdur. İnsidansı \% 0,033,5 arasında değişmektedir.[5,6] Genellikle cesarean section (C/S) gibi obstetrik veya jinekolojik cerrahi sırasında insizyon yerinde endometrial dokunun yayılmasından kaynaklanır. $[5,7,8]$ En sık klinik bulgusu boyutları değişiklik gösterebilen ve menstruasyon sırasındaki siklik ağrı oluşturan kitledir. [9] ADE'nin klinik görünümü, ortaya çıkma zamanı ve yeri oldukça değişkendir ve bu durum çoğu zaman preoperatif tanı koymayı zorlaştııı. Ayrıca tanıda abdominal ultrasonografi (US) ve abdominopelvik bilgisayarlı tomografi (BT) kullanılmasına karşın, kesin tanı için hangi yöntemin kullanılacağı konusunda klinisyenler arasında fikir birliği bulunmamaktadır. Bu nedenlerden dolayı, ADE fitık, lipom veya hematom ile karıştııılarak yanlış teşhis edilme riski taşımaktadır.[10]

Bu çalışmanın amacı, ADE olan hastalarda demografik ve klinik özellikleri, tanı araçlarını, cerrahi seçenekleri ve nüks oranlarını değerlendirmektir.

\section{Gereç ve Yöntemler}

Çalışma öncesinde etik kurul onayı, üniversitemiz Klinik Araştırmalar Etik Kurulu'ndan alındı. Bu çalışma tek merkezde, retrospektif ve gözlemsel bir çalışma olarak tasarlanmıştır ve Helsinki Deklarasyonu'na uygun olarak gerçekleştirilmiştir.

Ocak 2015 ile Ocak 2020 tarihleri arasından kliniğimizde ADE nedeniyle opere edilen (patolojik olarak da teyit edilen) 44 hasta çalışmaya dahil edildi. Hastanemiz veri tabanı incelenerek hastalara ait demografik veriler, operasyon geçmişi, klinik özellikler, tanı için kullanılan görüntüleme yöntemi, uygulanan operasyon tipi ve rekürrens durumu kayıt altına alındı.

\section{Bulgular}

Çalışmaya dahil edilen hastaların, yaşlarının median değeri 35 (26-48) olarak belirlendi. Hastaların doğum sayılarının ortanca değeri ise $1(0-3)^{\prime}$ di. Sadece $1(\% 2,3)$ hastanın daha önce herhangi bir abdominal operasyon öyküsü bulunmazken; 39 $(\% 88,6)$ hastanın C/S öyküsü bulunmaktadır. Diğer yandan geri 
kalan 4 hastanın da C/S öyküsü bulunmasına karşın; hastalara en son uygulanan cerrahi işlemlerin $2(\% 4,5)$ hastada myomektomi ve $2(\% 4,5)$ hastada da histerektomi olduğu tespit edildi. C/S sayılarına bakıldığında $27(\% 61,4)$ hastanın 1, $11(\% 25)$ hastanın 2 ve $5(\% 11,4)$ hastanın ise $3 \mathrm{C} / \mathrm{S}$ öyküsü bulunmaktadır.

Çalışmaya dahil edilen hastalardan $2(\% 4,5)$ 'sinin herhangi bir şikayeti bulunmazken, ADE insidental olarak tespit edilmiştir. Hastaların $31(\% 70,5)$ 'inde karın ön duvarında kitle şikayeti bulunurken, $39(\% 88,6)$ hastanın ise ağrı şikayeti bulunmaktaydı. Ağrı, $25(\% 64,1)$ hastada siklik, $14(\% 35,9)$ hastada non-siklik karakterde olduğu belirlendi.

ADE'nin $23(\% 52,3)$ hastada pfannenstiel insizyonun sol lateralinde, $17(\% 38,6)$ hastada pfannenstiel insizyonun sağ lateralinde, $1(\% 2,3)$ hastada median abdominal insizyon hattında, daha önce herhangi bir operasyon öyküsü olmayan 1 $(\% 2,3)$ hastada sol rektus kasının lateralinde ve $2(\% 4,5)$ hastada ise umblikusta yer aldığı tespit edildi. Ayrıca C/S öyküsü olan $1(\% 2,3)$ hastanın ADE'ne pelvik endometriozisinde eşlik ettiği belirlendi. Hastalara ait demografik veriler Tablo 1'de verilmiştir.

\begin{tabular}{lc}
\hline Tablo 1: Demografik Özellikler & $\mathrm{n}(\%)$ \\
\hline & $35(26-48)$ \\
\hline Yaş* & $1(0-3)$ \\
\hline Doğum Sayısı* & \\
\hline Eski Operasyon Öyküsü & $1(2,3)$ \\
\hline Operasyon Öyküsü yok & $39(88,6)$ \\
\hline Sezaryen & $2(4,5)$ \\
\hline Myomektomi & $2(4,5)$ \\
\hline Histerektomi & \\
\hline Sezaryen Sayısı & $1(2,3)$ \\
\hline 0 & $27(61,4)$ \\
\hline 1 & $11(25)$ \\
\hline 2 & $5(11,4)$ \\
\hline 3 & \\
\hline Semptom & $2(4,5)$ \\
\hline Asemptomatik & $31(70,5)$ \\
\hline Kitle & $39(88,6)$ \\
\hline Ağrı & \\
\hline Ağrı Karakteri & $25(64,1)$ \\
\hline Siklik & $14(35,9)$ \\
\hline Non-siklik & $23(52,3)$ \\
\hline Kitle Yerleşim Yeri & $17(38,6)$ \\
\hline Pfannenstiel İnsizyon Sol & $1(2,3)$ \\
\hline Pfannenstiel İnsizyon Sağ & $1(2,3)$ \\
\hline Median Abdominal İnsizyon & $2(4,5)$ \\
\hline Rektus Kasının Sol Laterali & $1(2,3)$ \\
\hline Umblikus & \\
\hline Pelvik Endometriozis Birlikteliği & \\
\hline Median (min-max). & \\
\hline
\end{tabular}

Hastaların 34'ünde preoperatif tanı aracı olarak abdominal US kullanılmış olup; bunlardan 29 (\%85,2)'unda ADE, 2 hastada desmoid tümör, 2 hastada sütur granulomu ve 1 hastada da nörofibroma preoperatif tanı olarak bildirilmiştir. Hastaların 10'unda ise abdominopelvik BT preoperatif tanı aracı olarak kullanılmış olup; bunlardan 5 (\%50)'inde ADE, 2 hastada desmoid tümör, 2 hastada inflamatuar granulom ve 1 hastada ise benign lipomatöz lezyon preoperatif tanı olarak belirlenmiştir. Ayrıca 3 hastanın preoperatif tanısında abdominal US'a ek olarak manyetik rezonans görüntüleme (MRI) kullanılmış olup, bu hastalarının tamamında preoperatif tanı olarak ADE bildirilmiştir. Preoperatif tanı araçlarına ait veriler Tablo 2'de verilmiştir.

\begin{tabular}{|c|c|c|}
\hline \multicolumn{3}{|c|}{ Tablo 2: Preoperatif Tanı Doğruluğu } \\
\hline $\begin{array}{l}\text { Preoperatif Tanı } \\
\text { Aracı }\end{array}$ & $\begin{array}{l}\text { Doğruluk } \\
(\%)\end{array}$ & DiğerTanı \\
\hline Abdominal US & $29 / 34(85,2)$ & $\begin{array}{l}\text { Desmoid tümör } 2 \text { hasta, } \\
\text { Nörofibroma } 1 \text { hasta, } \\
\text { Sütur granulomu } 2 \text { hasta }\end{array}$ \\
\hline $\begin{array}{l}\text { Abdominopelvik } \\
\text { BT }\end{array}$ & $5 / 10(50)$ & $\begin{array}{l}\text { İnflamatuar granulom } 2 \text { hasta } \\
\text { Desmoid tümör } 2 \text { hasta } \\
\text { Benign lipomatöz lezyon } 1 \\
\text { hasta }\end{array}$ \\
\hline US ve MRI & $3 / 3(100)$ & \\
\hline $\begin{array}{l}\text { US: Ultrasonogra } \\
\text { zonans görüntült }\end{array}$ & BT: Bilgisaya & mografi, MRI: Manyetik re- \\
\hline
\end{tabular}

Tedavi prosedürü olarak hastaların tamamına geniş eksizyon işlemi uygulanmıştır. Eksizyon işlemine ek olarak 2 (\%4,5) hastada geniş fasya defekti oluşması nedeniyle mesh kullanılmıştır. ADE'e ek olarakpelvikendometriozis tespit edilen $1(\% 2,3)$ hastaya da eksizyon işlemi ile birlikte sol salpingoooferektomi işlemi uygulanmıştır. Ayrıca $2(\% 4,5)$ hastaya cerrahi tedaviye ek olarak medikal tedavi de (gonadotropinreleasing hormon) uygulandığı tespit edilmiştir. Tedavi prosedürü ve cerrahi tedavi ek medikal tedaviye ait veriler Tablo 3'te gösterilmiştir.

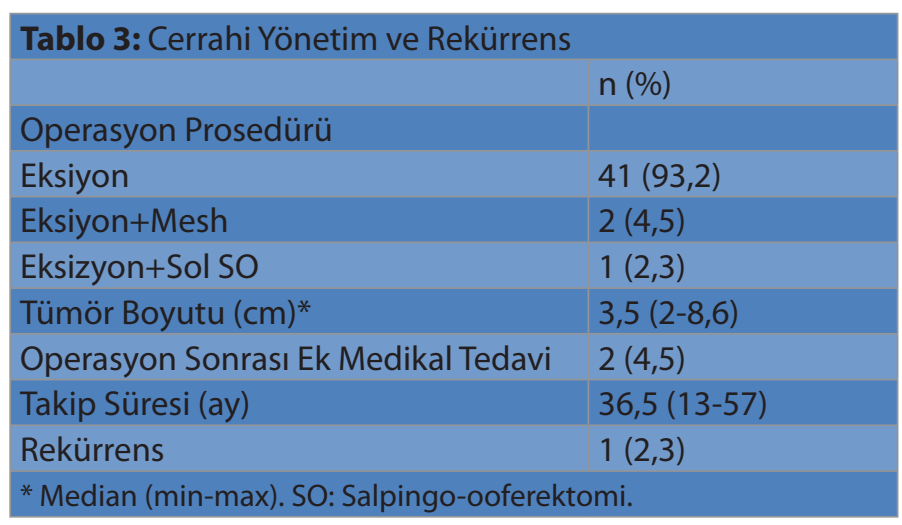


Hastalarımızdan $42(\% 95,4)$ 'sinin takiplerine devam ettiği tespit edilmiş olup, serimizdeki takip süresi median değerinin 36,5 ay (13-57) olduğu gösterilmiştir. Ayrıca 1(\%2,3) hastanın takiplerinde rekürrens geliştiği belirlenmiştir. $\mathrm{Bu}$ hastaya reeksizyon önerilmiş fakat hastanın reoperasyonu reddetmesi nedeniyle uygulanamadığı tespit edilmiştir. Takip süresi ve rekürrense ait veriler Tablo 3'te verilmiştir.

\section{Tartışma}

$A D E$, oldukça nadir olmakla birlikte, pelvik veya jinekolojik operasyon öyküsü olan kadınlardaki prevelansı \% 0,03-1,08 olarak bildirilmiştir.[11] Nadir olarak ortaya çıkmasına karşın, tespit edildiği takdirde derhal tedavi edilmesi gerekmektedir. Çünkü literatürde, ADE zemininde clear cell carcinoma and adenocarcinoma geliştiği bildirilmiştir.[12-14]

Patogenezi için çeşitli hipotezler ortaya atılmasına rağmen literatürde net bir fikir birliği bulunmamaktadır. En çok üzerinde durulan hipotez ise, $\mathrm{C} / \mathrm{S}$ işlemi sırasında endometrial dokunun abdominal fasya ve subkutan dokuya iatrojenik implantasyonudur.[15] Ancak bu hipotezin aksine, ADE vakalarının \%20'sinde cerrahi öyküsü olmadığı bildirilmiştir. [10] Cerrahi öyküsü olmayan bu hasta grubunda ise, ADE'nin endometriyal dokunun hematojen veya lenfatik yayılmasının bir sonucu olduğuna inanılmaktadır.[10] Gerçekleştirdiğimiz bu çalışmada, sadece bir hastanın operasyon öyküsü bulunmazken; kalan hastaların tamamında C/S başta olmak üzere en az bir operasyon öyküsü bulunmaktadır. Bu konunun aydınlatılması adına, ilerleyen zamanda yapılacak deneysel çalışmaların literatüre katkı sağlayacağına inanıyoruz.

Klinik olarak, ADE'n en sık görülen semptomları kitle ve ağrıdır. $[10,16]$ Literatürle uyumlu olarak bizim serimizde de kitle ve ağrı semptomunun yoğunlukta olduğu belirlenmiştir. Ağrının ise ağırlıklı olarak siklik karakterde olduğu gösterilmiştir. Ayrıca 2 hastanın herhangi bir şikayeti bulunmamasına rağmen; başka bir neden için yapılan araştırmada, pfannenstiel insizyon hattında insidental olarak kitle tespit edilmiştir.

ADE'nin nadir olarak görülmesi ve sıklıkla sütur granülomu, yumuşak doku sarkomu, desmoid tümör gibi bazı hastalıklarla karışması, preoperatif tanıyı oldukça güçleştirmektedir. Şöyle ki; preoperatif klinik tanı doğruluğunun \%26 ile \%70 arasında değiştiği bildirilmiştir.[9,16,17] Preoperatif tanıda kullanılan en sık yöntemler arasında abdominal US, abdominopelvik BT, abdominapelvik MRI ve US klavuzluğunda ince iğne aspirasyon biyopsisi (ïAB) yer almaktadır.[18-19] Bizde literatürle uyumlu olarak preoperatif tanı aracı olarak çoğunlukla abdominal US ve daha az oranda abdominopelvik BT'yi kullandık. Serimizde, abdominal US'nin doğruluk oranı \%85 üzerinde iken, BT'nin doğruluk oranının \%50'de kaldığı tespit edilmiştir. Ortaya çıkan bu sonucun, abdominal US'nin avantajlarından biri olan radyologun US uygulaması sırasında karın duvarındaki hassas noktayı belirleyebilmesinden kaynaklanabileceğini düşünüyoruz.[20] Ayrıca çalışmamızda, US ve MRI'nin birlikte kullanıldığı 3 hastada doğruluk oranının \%100 olması dikkat çekicidir. Öte yandan doğruluk oranının düşük olması nedeniyle hiçbir hastada preoperatif tanı aracı olarak iiAB'ni tercih etmedik.[16] Ancak Song HK ve arkadaşları, 38 hastanın dahil edildiği çalışmasında, preoperatif uygulanan görüntüleme yöntemlerinde hiçbir hastada malignite tespit edilmemesine rağmen, 3 hastanın postoperatif patolojisinde malignite tespit edilmesi nedeniyle, preoperatif dönemde ADE'nden şüphelenilen durumlarda IïAB önermektedir.[21] Diğer yandan IiAB işlemi, uygulama yerinde implantasyon için risk oluşturmaktadır.[22,23] Görünen o ki; bu konuda fikir birliği oluşabilmesi için geniş serili ve prospektif çalışmalara ihtiyaç vardır. Biz ise klinik tecrübemize dayanarak, preoperatif tanı aracı olarak öncelikle abdominal US'yi ve şüpheli bazı durumlarda ise abdominal US'ye ek olarak abdominopelvik MRI'yi öneriyoruz.

ADE'nin en yaygın tedavi seçenekleri medikal tedavi ve cerrahidir.[2,24] Medikal tedavide amaç, hormonların lezyon üzerindeki etkisini azaltarak semptomların giderilmesidir; ancak medikal tedavi uygulanan çoğu hastada cerrahi eksizyon gerekli olmaktadır.[18] Bu nedenle ADE tedavisinde cerrahi eksizyon, hem tanıda hem de tedavide en etkili seçenek olarak karşımıza çıkmaktadır. Çalışmamızdaki tüm hastalara, Kim SM ve arkadaşlarının çalışmasında önerildiği gibi en az $1 \mathrm{~cm}$ 'lik temiz cerrahi sınırlar sağlanacak şekilde cerrahi eksizyon işlemi uygulanmıştır.[25] Fakat gerçekleştirdiğimiz literatür araştırmasında, temiz cerrahi sınır büyüklüğünün rekürrensdeki rolünü inceleyen çalışmaya rastlamadık. Ayrıca literatürde de önerildiği gibi, insizyonel herniyi önlemek adına 2 hastada cerrahi eksizyona ek olarak polipropilen mesh kullandık.[8,22,24] Takiplerimizde hastaların hiçbirinde insizyonel herni gelişmediğini belirledik. Diğer yandan ADE'ne ek olarak pelvik endometriozisi olan 1 hastada, ADE cerrahi olarak eksize edilirken pelvik endometriozis için ise salpingo-ooferektomi tercih edilmiştir. Ayrıca 2 hastaya ise cerrahi eksizyona ek olarak medikal tedavi de (gonadotropinreleasing hormon) verildiği belirlendi.

Gerçekleştirdiğimiz literatür incelemesinde, düşük rekürrens oranlarının $(\% 4,5-9,1) \quad$ olduğunu tespit ettik.[16,26] Çalışmamızda ise sadece $1(\% 2,3)$ 'inde rekürrens geliştiği tespit edildi. Hasta, ADE nedeniyle cerrahi işlem uygulanmasından 22 ay sonra aynı lokalizasyonda ağrılı şişlik nedeniyle tekrar başvuru yaptı. Abdominal US'de nüks ADE belirlenmesi üzerine tekrar operasyona alındı. Geniş eksizyonun yanı sıra mesh kullanıldı. Bu hastanın daha sonraki takiplerinde nüks tespit edilmedi. 


\section{Sonuç}

$A D E$, jinekolojik girişim öyküsü olan ve abdominal insizyon bölgesinde siklik ağrı ve şişlik ile gelen reprodüktif çağdaki tüm kadınlarda akla gelmelidir. Preoperatif tanı için, hastanın öyküsü ayrıntılı olarak sorgulanmalı; dikkatli bir fizik muayene yapılmalı ve abdominal US ilk tercih edilecek görüntüleme yöntemi olarak kullanılmalıdır. Ayrıca ADE'nde tercih edilmesi gereken tedavi seçeneği cerrahi eksizyondur.

\section{Çıkar çatışması / finansal destek beyanı}

Bu yazıdaki yazarların herhangi bir çıkar çatışması yoktur. Yazının herhangi bir finansal desteği yoktur.

\section{Kaynaklar}

1. Nezhat FR, Shamshirsaz AA, Yildirim G. Pelvic pain, endometriosis, and the role of the gynecologist. Pediatric, Adolescent and Young Adult Gynecology. 1st ed. New Jersey:Wiley-Blackwell; 2009:174-94.

2. Alessandro P, Luigi N, Felice $S$, Maria PA, Benedetto MG, Stefano A. Research development of a new GnRH antagonist (Elagolix) for the treatment of endometriosis: A review of the literature. Arch Gynecol Obstet 2017; 295: 827-32.

3. Sarma D, terBrugge KG, Gentili F, Halliday W. Cerebellar Endometriosis. AJR Am J Roentgenol 2004; 182: 1543-6.

4. Huang $\mathrm{H}$, Li C, Zarogoulidis $\mathrm{P}$ et al. Endometriosis of the lung: report of a case and liter- ature review. Eur J Med Res 2013; 18: 13.

5. Leite GKC, de Carvalho LFP, Korkes $\mathrm{H}$ et al. Scar endometrioma following obstetric surgical incisions: retrospective study on 33 cases and review of the literature. Sao Paulo Med J 2009; 127: 270-7.

6. Uçar MG, Şanlıkan F, Göçmen A. Surgical treatment of scar endometriosis following cesarean section, a series of 12 cases. Indian J Surg 2015; 77: 682-6.

7. Rindos NB, Mansuria S. Diagnosis and management of abdominal wall endometriosis: a systematic review and clinical recommendations. Obstet Gynecol Surv 2017; 72: 116-22.

8. Blanco RG, Parithivel VS, Shah AK, Gumbs MA, Schein M, Gerst $\mathrm{PH}$. Abdominal wall endometriomas. Am J Surg 2003; 185: 596-8.

9. Chang $\mathrm{Y}$, Tsai EM, Long $\mathrm{CY}$, Chen $\mathrm{YH}$, Kay N. Abdominal wall endometriomas. J Reprod Med 2009; 54: 155-9.

10. Horton JD, Dezee KJ, Ahnfeldt EP, Wagner M. Abdominal Wall endometriosis: A surgeon's perspective and review of 445 cases. Am J Surg 2008; 196: 207-12.

11. Nominato NS, Prates LF, Lauar I, Morais J, Maia L, Geber S. Caesarean section greatly increases risk of scar endome- triosis. Eur J Obstet Gynecol Reprod Biol 2010; 152: 83-5.

12. Taburiaux L, Pluchino N, Petignat P, Wenger JM. Endometriosisassociated abdominal wall cancer: a poor prognosis? Int J Gynecol Cancer 2015; 25: 1633-8.
13. Ferrandina G, Palluzzi E, Fanfani F et al. Endometriosis-associated clear cell carcinoma arising in caesarean section scar: a case report and review of the literature. World J Surg Oncol 2016; 14: 300.

14. Modesitt SC, Tortolero-Luna G, Robinson JB, Gershenson DM, Wolf JK. Ovarian and extraovarian endometriosis- associated cancer. Obstet Gynecol 2002; 100: 788-95.

15. Khachani I, Filali Adib A, Bezad R. Cesarean scar endometriosis: An uncommon surgical complication on the rise? Case report and literature review. Case Rep Obstet Gynecol 2017; 80: 629-24.

16. Bektas H, Bilsel Y, Sari YS et al. Abdominal wall endo- metrioma; a 10-year experience and brief review of the literature. J Surg Res 2010; 164: e77-e81.

17. Fernandez-Acenero MJ, Cordova S. Cutaneous endome- triosis: review of 15 cases diagnosed at a single institution. Arch Gynecol Obstet 2011; 283: 1041-4.

18. Oh EM, Lee WS, Kang JM, Choi ST, Kim KK, Lee WK. A surgeon's perspective of abdominal wall endometriosis at a caesarean section incision: Nine cases in a single institution. Surg Res Pract 2014; 2014: 765372.

19. Medeiros Fd, Cavalcante DI, Medeiros MA, Eleutério J Jr. Fineneedle aspiration cytology of scar endometriosis: Study of seven cases and literature review. Diagn Cytopathol 2011; 39: 18-21.

20. Savelli L, Manuzzi L, Donato ND et al. Endometriosis of the abdominal wall: ultrasonographic and doppler characteristics. Ultrasound Obstet Gynecol 2011; 10052: 132.

21. Song HK, Lee SH, Kim MJ, Shin JE, Lee DW, Lee HN. Abdominal wall mass suspected of endometriosis: clinical and pathologic features. Obstet Gynecol Sci 2020; 63: 357-62.

22. Patterson GK, Winburn GB. Abdominal wall endometriomas: Report of eight cases. Am Surg 1999; 65: 36-9.

23. Grigore M, Socolov D, Pavaleanu I, Scripcariu I, Grigore AM, Micu R. Abdominal wall endometriosis: an update in clinical, imagistic features, and management options. Med Ultrason 2017; 19:430-7.

24. Purvis RS, Tyring SK. Cutaneous and subcutaneous endome- triosis. Surgical and hormonal therapy. J Derm Surg Oncol 1994; 20: 693-5.

25. Kim SM, Kim HK, Namkung J et al. A case of reconstruction of abdominal fascia using polypropylene mesh for patient of abdominal wall endometriosis after cesarean section. Korean J Obstet Gynecol 2012; 55: 517-21.

26. Khan Z, Zanfagnin V, El-Nashar SA, Famuyide AO, Daft- ary GS, Hopkins MR. Risk factors, clinical presentation, and outcomes for abdominal wall endometriosis. J Minim Invasive Gynecol 2017; 24: 478-84. 